\title{
Diving behaviour during the internesting interval for loggerhead turtles Caretta caretta nesting in Cyprus
}

\author{
Jonathan D. R. Houghton ${ }^{1}$, Annette C. Broderick ${ }^{1}$, Brendan J. Godley ${ }^{1}$, \\ Julian D. Metcalfe ${ }^{2}$, Graeme C. Hays ${ }^{1, *}$ \\ ${ }^{1}$ School of Biological Sciences, University of Wales Swansea, Singleton Park, Swansea SA2 8PP, United Kingdom \\ ${ }^{2}$ The Centre for Environment, Fisheries and Aquaculture Science (CEFAS), Lowestoft Laboratory, Pakefield Road, Lowestoft, \\ Suffolk NR33 0HT, United Kingdom
}

\begin{abstract}
Time depth recorders were used to assess the patterns of depth utilisation by 2 loggerhead turtles Caretta caretta in Cyprus, eastern Mediterranean. Dives to the seabed accounted for $59 \%(171 \mathrm{~h})$ and $75 \%(215 \mathrm{~h})$ of the internesting interval, respectively, with most dives being shallow $(<20 \mathrm{~m})$, suggesting the turtles remained close to the shore. These benthic dives decreased markedly in the days following or prior to a nesting event, suggesting that the behaviours associated with nesting may be protracted. This importance of the seabed for loggerhead turtles in Cyprus contrasts with the far more extensive use of mid-water resting dives recently reported for this species in Japan. Our evidence suggests that this dichotomy may reflect differences in the amount of time spent travelling, with mid-water resting occurring when turtles are travelling and, conversely, when little time is spent travelling turtles opt to remain predominantly on the seabed.
\end{abstract}

KEY WORDS: Sea turtle $\cdot$ Diving $\cdot$ Wildlife telemetry $\cdot$ Mediterranean $\cdot$ Internesting interval

Resale or republication not permitted without written consent of the publisher

\section{INTRODUCTION}

Over recent years, the development of electronic logging devices such as time depth recorders (TDRs) has allowed us to look more closely at the diving behaviour of marine turtles at nesting grounds (e.g. Eckert et al. 1986). It has become apparent that behaviours during the internesting interval (i.e. the period between nesting events) may be highly adapted to local conditions. For example, at sites where no food is available, green turtles Chelonia mydas may maximise their resources available for reproduction through energy saving strategies such as resting on the seabed (e.g. Hays et al. 2000) while at sites where food is more abundant they may forage (e.g. Hochscheid et al. 1999). Similarly, studies with loggerhead turtles $\mathrm{Ca}$ retta caretta have shown behavioural plasticity during the internesting interval. For example, loggerheads in Japan may rest on the seabed (Minamikawa et al.

*Corresponding author. E-mail: g.hays@swansea.ac.uk
1997), feed pelagically in deep water (Sakamoto et al. 1990) or spend long periods resting in mid-water (Minamikawa et al. 2000). In addition to these interindividual differences in behaviour, there is some evidence to suggest that the behaviour of individual turtles may not be invariant throughout the internesting interval. For example, Hays et al. (1999) showed that green turtles, which had predominantly rested at the seabed throughout the internesting interval, became less quiescent and spent more time close to the surface as the time for nesting approached. This is consistent with the findings of Hays et al. (1991), who used satellite telemetry to infer that a loggerhead turtle in Greece spent more time near the surface as it approached nesting dates.

We can hypothesise that the internesting behaviour of marine turtles is driven by the optimisation of energy reserves in a manner most suited to localised conditions and to the processes associated with nesting (e.g. the relocation of the nesting site). Given the potential array of behaviours this encompasses, we set out to investigate the internesting behaviour of logger- 
head turtles in Cyprus, a site which provided a huge range of water depths (from a few to thousands of metres) close to the nesting beach and hence a correspondingly wide range of potential depth utilisation patterns by turtles. Our fundamental objectives were (1) to assess the patterns of depth utilisation by turtles and hence infer whether pelagic or benthic habitats were most important, and (2) to consider how behaviours changed over the internesting period.

\section{MATERIALS AND METHODS}

TDRs. Between 19 June and 1 July 1999 we attached LTD_100 (Light Temperature Depth) archival storage tags (Lotek, St John's, Canada) to 5 female loggerhead turtles Caretta caretta nesting on Alagadi beach, Cyprus $\left(35^{\circ} 21^{\prime} \mathrm{N}, 33^{\circ} 30^{\prime} \mathrm{E}\right)$. Each tag was programmed to record depth (range 0 to $100 \mathrm{~m}$, resolution $0.06 \mathrm{~m}$ ) every $5 \mathrm{~s}$, light intensity (dimensionless units but varying between 0 and 1 ) and temperature (range -20 to $+35^{\circ} \mathrm{C}$, resolution $0.03^{\circ} \mathrm{C}$ ) every $10 \mathrm{~min}$. To prevent damage or loss through impact, tags were secured in open-ended Perspex casings and attached to the carapace using epoxy resin (Foilfast, SFS components, Cheltenham, UK). These were retrieved when the turtles returned to Alagadi to lay their subsequent clutches.

Analysis of dive data. All dive data were analysed using Multitrace analysis software (Jensen Software Systems, Laboe, Germany). Submergence was classified as a 'dive' if its maximum depth (measured from the surface) exceeded $0.75 \mathrm{~m}$. For dives with a maxi- mum depth $>3 \mathrm{~m}$, each dive was separated into distinct phases on the basis of vertical velocity alone, using a threshold value of $0.03 \mathrm{~m} \mathrm{~s}^{-1}$. For example, the beginning of the descent phase would begin once a turtle's rate of descent exceeded the threshold value and would finish once the rate decreased below it (i.e. the beginning of the bottom phase).

For shallower dives $(>0.75$ and $<3 \mathrm{~m})$ it was necessary to introduce an additional parameter, 'level end of diving' (LoD) which considers the end of a dive as the point where the animal has exceeded a certain percentage of the maximum depth recorded for that dive. This was required as threshold velocity alone could not consistently detect the beginning and end of such dives owing to their gentle ascent and descent rates. Trials with the software suggested that an LoD of $75 \%$ was most applicable to the data set.

\section{RESULTS}

\section{Identification of dive types}

Two of the 5 TDRs were retrieved (termed Turtles 1 and 2) with internesting intervals of $12 \mathrm{~d}$ in each case. Individual dives were classified as 1 of 6 types corresponding to the work of Minamikawa et al. (1997), Hochscheid et al. (1999) and Hays et al. (2000) (Fig. 1). Related dive statistics for each dive type by both turtles can be seen in Tables 1 \& 2 .

Type 1 dives were characterised by a steep descent phase, a distinctive bottom phase, and a steep ascent, consistent with the Type 1 dives described by Mi-
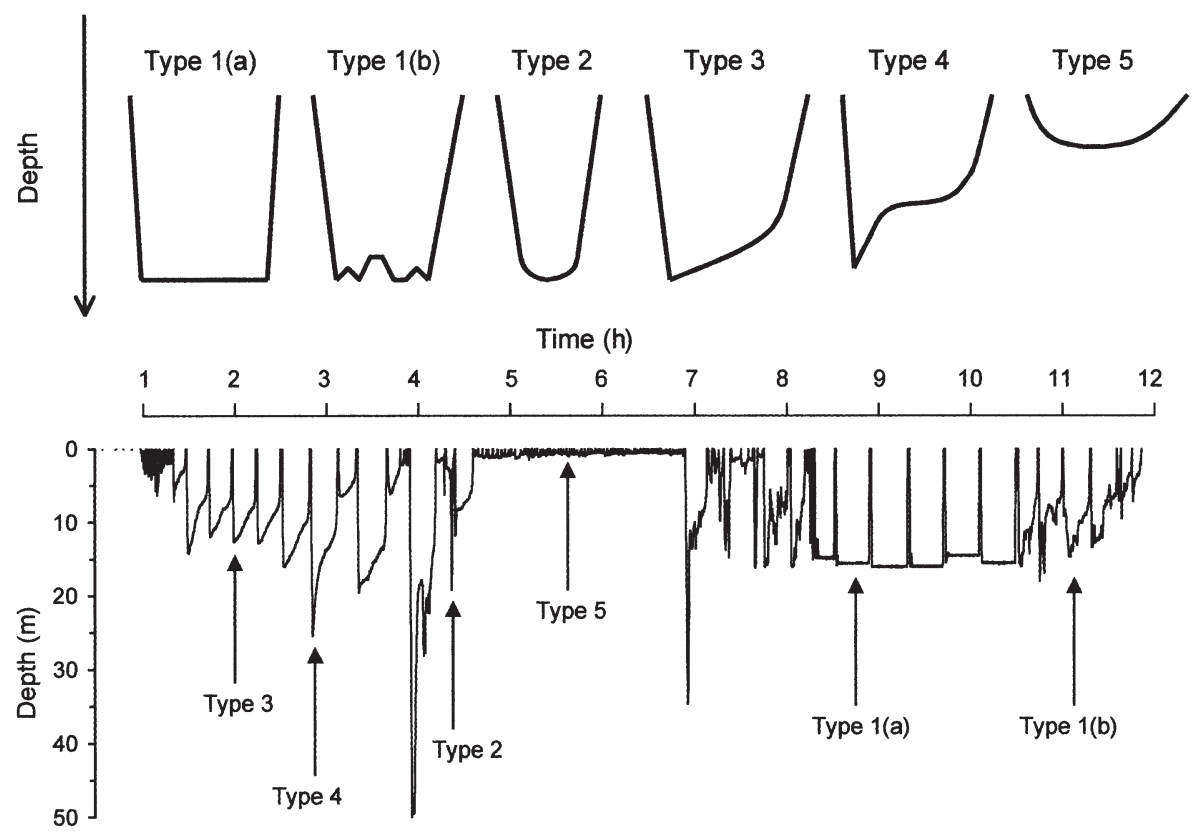

Fig. 1. Generalised diagram (top panel) and typical dive profile for turtle 1 (bottom panel) highlighting the 6 dive types 
Table 1. Mean values for the maximum depth and duration of each dive type $( \pm 1$ SD) for Turtles 1 and 2. Additionally shown are the relationships between depth and duration (linear regression) and the time attributable to each dive type throughout the internesting interval. ns: not significant

\begin{tabular}{|c|c|c|c|c|c|c|}
\hline & Type 1(a) & Type 1(b) & Type 2 & Type 3 & Type 4 & Type 5 \\
\hline \multicolumn{7}{|c|}{ Dive characteristics for Turtle 1} \\
\hline Depth $(\mathrm{m})$ & $7.51 \pm 2.51$ & $7.51 \pm 4.09$ & $7.71 \pm 9.53$ & $8.85 \pm 5.22$ & $15.10 \pm 9.28$ & $1.50 \pm 0.58$ \\
\hline Duration (min) & $36.20 \pm 4.52$ & $6.94 \pm 5.87$ & $1.66 \pm 1.37$ & $14.21 \pm 9.16$ & $16.38 \pm 11.51$ & $4.31 \pm 4.14$ \\
\hline $\begin{array}{l}\text { Depth }(x) \\
\text { vs duration }(y)\end{array}$ & $y=0.49 x+32.49$ & $y=0.52 x+3.05$ & $y=0.11 x+0.80$ & $y=0.94 x+5.86$ & $y=0.52 x+8.53$ & $y=2.21 x+0.99$ \\
\hline Regression & $\begin{array}{c}F_{1,264}=21.42 \\
\mathrm{r}^{2}=0.07 \mathrm{p}<0.001\end{array}$ & $\begin{array}{c}F_{1,145}=21.64 \\
\mathrm{r}^{2}=0.13 \mathrm{p}<0.001\end{array}$ & $\begin{array}{c}F_{1,69}=98.40 \\
\mathrm{r}^{2}=0.59 \mathrm{p}<0.001\end{array}$ & $\begin{array}{c}F_{1,46}=18.96 \\
\mathrm{r}^{2}=0.29 \mathrm{p}<0.001\end{array}$ & $\begin{array}{c}F_{1,38}=8.10 \\
\mathrm{r}^{2}=0.18 \mathrm{p}<0.05\end{array}$ & $\begin{array}{c}F_{1,867}=94.02 \\
\mathrm{r}^{2}=0.10 \mathrm{p}<0.05\end{array}$ \\
\hline $\begin{array}{l}\text { Proportion } \\
\text { of INP (\%) }\end{array}$ & 54.86 & 6.28 & 0.57 & 3.83 & 3.40 & 22.60 \\
\hline \multicolumn{7}{|c|}{ Dive characteristics for Turtle 2} \\
\hline Depth (m) & $9.91 \pm 3.56$ & $7.65 \pm 4.21$ & $4.81 \pm 1.69$ & $6.39 \pm 2.45$ & $6.09 \pm 2.85$ & $1.91 \pm 0.59$ \\
\hline Duration (m) & $22.49 \pm 6.04$ & $5.64 \pm 4.35$ & $1.15 \pm 0.47$ & $3.38 \pm 2.15$ & $3.67 \pm 1.56$ & $1.36 \pm 2.22$ \\
\hline $\begin{array}{l}\text { Depth }(x) \\
\text { vs duration }(y)\end{array}$ & $y=1.15 x+11.45$ & $y=0.38 x+2.77$ & $y=0.10 x+0.65$ & $y=0.18 x+2.21$ & $\mathrm{~ns}$ & $y=0.61 x+0.20$ \\
\hline Regression & $\begin{array}{c}F_{1,546}=416.32 \\
\mathrm{r}^{2}=0.43 \mathrm{p}<0.001\end{array}$ & $\begin{array}{c}F_{1,247}=37.7 \\
\mathrm{r}^{2}=0.13 \mathrm{p}<0.001\end{array}$ & $\begin{array}{c}F_{1,323}=51.67 \\
\mathrm{r}^{2}=0.14 \mathrm{p}<0.001\end{array}$ & $\begin{array}{c}F_{1,88}=4.01 \\
\mathrm{r}^{2}=0.04 \mathrm{p}<0.001\end{array}$ & $\begin{array}{c}\mathrm{ns} \\
(\mathrm{p}>0.05)\end{array}$ & $\begin{array}{c}F_{1,767}=19.55 \\
\mathrm{r}^{2}=0.02 \mathrm{p}<0.0001\end{array}$ \\
\hline $\begin{array}{l}\text { Proportion } \\
\text { of INP (\%) }\end{array}$ & 70.71 & 4.99 & 2.21 & 1.72 & 0.34 & 6.41 \\
\hline
\end{tabular}

namikawa et al. (1997) and the 'U' dives of Hochscheid et al. (1999) and Hays et al. (2000). Closer analysis suggested that Type 1 dives could be further classified on the basis of vertical velocities, bottom profile and the proportion of the dive attributable to the bottom phase. Subsequently, principal component analysis (correlation matrix) was conducted using dive duration, maximum depth, duration of descent phase as a percentage of total dive duration, duration of bottom phase as a percentage of total dive duration, duration of ascent phase as a percentage of total dive duration and variation in depth during bottom phase. This analysis indicated 2 groupings (termed 1(a) and 1(b)): Type 1(a) dives were characterised by a steep descent phase, a flat bottom phase, and a steep ascent phase. Type 1(b) also displayed steep ascent and descent rates (though the latter was markedly less than that of 1(a) dives) but differed in their more erratic bottom profile (mean SD of depth during bottom phase $=0.61 \mathrm{~m}$ ) and the proportion of the dive attributable to the bottom phase $($ mean Type $1(\mathrm{a})=96 \%, \mathrm{SD}=3.64 ;$ mean Type $1(\mathrm{~b})=$ $75 \%, \mathrm{SD}=1.59$ ) (Fig. 1, Tables $1 \& 2$ ). To further test this discrimination, equations were derived for depth versus duration for Type 1(a) dives, and employed to make predictions of duration over a wide range of depths (1 to $30 \mathrm{~m})$. When the depth of Type 1(b) dives was plotted against their respective duration, durations were always below the $95 \%$ confidence limits of the relationship between depth and duration for Type 1 (a) dives for each individual, supporting their classifi-

Table 2. Vertical velocity $\left(V_{\mathrm{v}}\right)$ of different dive stages for each dive type $( \pm 1 \mathrm{SD})$ for Turtles 1 and 2

\begin{tabular}{|lcccccc}
\hline & Type 1(a) & Type 1(b) & Type 2 & Type 3 & Type 4 & Type 5 \\
\hline Turtle 1 & & & & & \\
Descent $V_{\mathrm{v}}\left(\mathrm{m} \mathrm{s}^{-1}\right)$ & $0.23 \pm 0.07$ & $0.21 \pm 0.09$ & $0.20 \pm 0.09$ & $0.22 \pm 0.13$ & $0.22 \pm 0.17$ & $0.09 \pm 0.05$ \\
Initial ascent $V_{\mathrm{v}}{ }^{\mathrm{a}}\left(\mathrm{m} \mathrm{s}^{-1}\right)$ & - & - & - & - & $0.04 \pm 0.05$ & - \\
Gradual ascent $V_{\mathrm{v}} \mathrm{b}\left(\mathrm{m} \mathrm{s}^{-1}\right)$ & - & - & $0.001 \pm 0.03$ & $0.06 \pm 0.005$ & $0.01 \pm 0.02$ & $0.001 \pm 0.008$ \\
Final ascent $V_{\mathrm{v}}\left(\mathrm{m} \mathrm{s}^{-1}\right)$ & $0.26 \pm 0.05$ & $0.16 \pm 0.07$ & $0.17 \pm 0.08$ & $0.11 \pm 0.07$ & $0.04 \pm 0.03$ & $0.07 \pm 0.04$ \\
Turtle 2 & & & & & \\
Descent $V_{\mathrm{v}}\left(\mathrm{m} \mathrm{s}^{-1}\right)$ & $0.37 \pm 0.13$ & $0.31 \pm 0.14$ & $0.29 \pm 0.13$ & $0.30 \pm 0.09$ & $0.26 \pm 0.17$ & $0.16 \pm 0.06$ \\
Initial ascent $V_{\mathrm{v}}{ }^{\mathrm{a}}\left(\mathrm{m} \mathrm{s}^{-1}\right)$ & - & - & - & - & $0.05 \pm 0.05$ & - \\
Gradual ascent $V_{\mathrm{v}} \mathrm{b}\left(\mathrm{m} \mathrm{s}^{-1}\right)$ & - & - & $0.006 \pm 0.03$ & $0.01 \pm 0.007$ & $0.01 \pm 0.03$ & $0.006 \pm 0.01$ \\
Final ascent $V_{\mathrm{v}}\left(\mathrm{m} \mathrm{s}^{-1}\right)$ & $0.27 \pm 0.08$ & $0.15 \pm 0.08$ & $0.16 \pm 0.09$ & $0.09 \pm 0.04$ & $0.06 \pm 0.04$ & $0.10 \pm 0.05$
\end{tabular}

${ }^{\mathrm{a}}$ Initial ascent phase only present in Type 4 dives

${ }^{\mathrm{b}}$ Gradual ascent phase only present in Type 3 and 4 dives. For Type 2, gradual ascent phase refers to the bottom phase of the dive 
cation as an independent dive type. For example, a Type 1(a) dive of $7.65 \mathrm{~m}$ (i.e. the mean depth of Type 1(b) dives for Turtle 2) had a predicted duration of 20 min whereas the actual value for Type 1(b) dives of similar depth was 7 min.

Type 2 dives displayed a 'V-shaped' profile with a bottom phase that suggested the turtle began to ascend immediately after maximum depth was attained (Fig. 1, Tables $1 \& 2$ ). This implies that activity at the point of maximum depth was minimal, consistent with the Type 2 dives described by Minamikawa et al. (1997) and the 'V-dives' of Hochschied et al. (1999).

Type 3 dives were identified as having a steep descent phase, followed by a gradual ascent phase and a
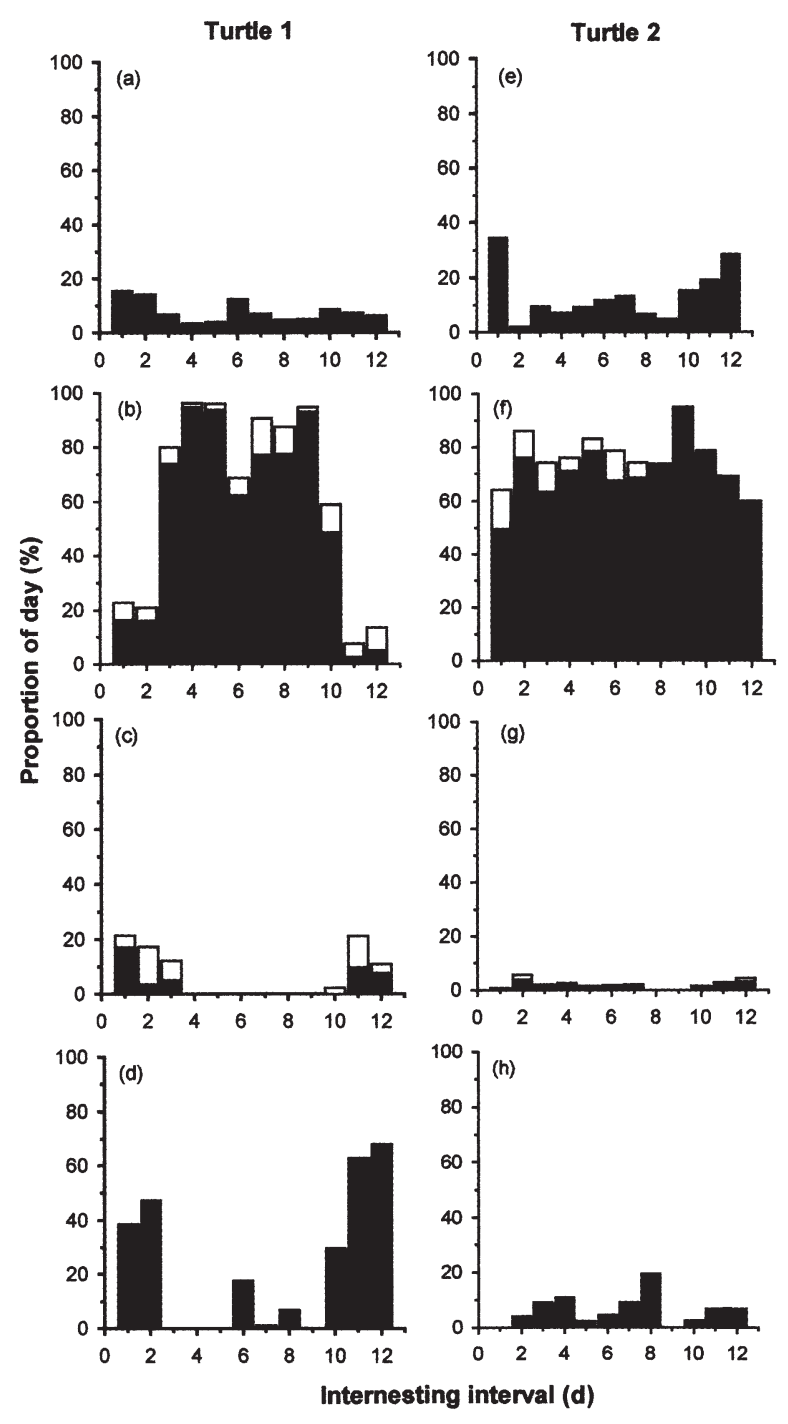

Fig. 2. Proportion of each day attributable to each dive type for Turtles 1 and 2 respectively. (a) and (e) show the time spent at the surface. (b) and (f) show the time spent diving to the seabed (Type 1(a): $\mathbf{\square}$; Type 1(b): $\square$. (c) and (g) show Type $3 \square$ and Type 4 dives $\square$. (d) and (h) show Type 5 dives steep final ascent. Such dives have been previously reported by Minamikawa et al. (1997) and attributed to the turtles gradually ascending from the point of maximum depth.

Type 4 dives were similar to Type 3 dives with the exception of a steep initial ascent phase following the point of maximum depth and preceding the gradual ascent phase. Such dives have been previously reported in the sea snake Pelamis platurus (Graham et al. 1987) and are comparable to the Type 4 dives described by Minamikawa et al. (1997), and the 'Sdives' of Hochscheid et al. (1999) in marine turtles.

Type 5 dives were classified on the basis of depth (i.e. $>0.75$ and $<3 \mathrm{~m}$ ) and their gradual descent and ascent phases which resulted in their typically shallow profile, comparable to the shallow sub-surface dives reported by Hochscheid et al. (1999).

\section{Temporal patterns in the importance of different dive types}

The time attributable to each dive Type throughout the internesting interval can be seen in Fig. 2. Although distinct differences are evident between the 2 turtles, Type 1(a) dives represent the prominent behaviour on most days. It is widely accepted that the bottom phase of such dives represent time at the seabed (see Minamikawa et al. 1997, Hochscheid et al. 1999, Hays et al. 2000). Correspondingly, when combined with Type 1(b) dives, this suggests that Turtles 1 and 2 spent $59 \%(171 \mathrm{~h})$ and $75 \%(215 \mathrm{~h})$ of the internesting interval on the seabed, respectively. For both turtles, the numbers of Type 1(a) dives decreased prior to, and following, a nesting event. For Turtle 1, this could be explained by an increase in Type 3, 4 and 5 dives; while for Turtle 2, the decrease in Type 1(a) dives could be better explained by the turtle spending

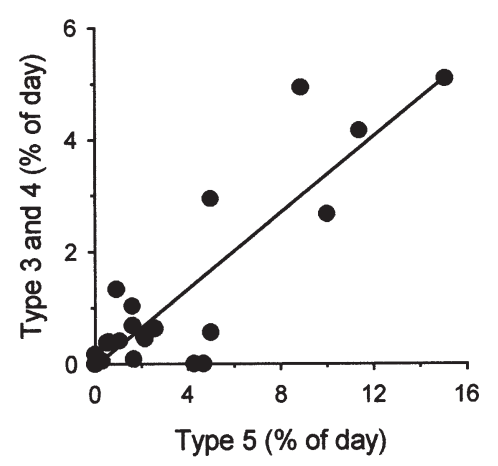

Fig. 3. Relationship between the number of Type 5 dives and dives with a gradual ascent phase (Types 3 and 4 ) during each day of the internesting interval for both turtles $\left(F_{1,22}=\right.$ $\left.73.78, \mathrm{r}^{2}=0.77, \mathrm{p}<0.0001\right)$ 
more time at the surface during Days 1 and 10 to 12 . The occurrence of Type 5 dives seemed to be linked to the occurrence of Type 3 and 4 dives: when Type 5 dives occurred more frequently, so did Type 3 and 4 dives (Fig. 3).

Certain distinct diel patterns of behaviour were evident (Fig. 4). For example, Type 5 dives occurred predominately during the daytime for Turtle 1, while for Turtle 2 these dives occurred mostly at night.
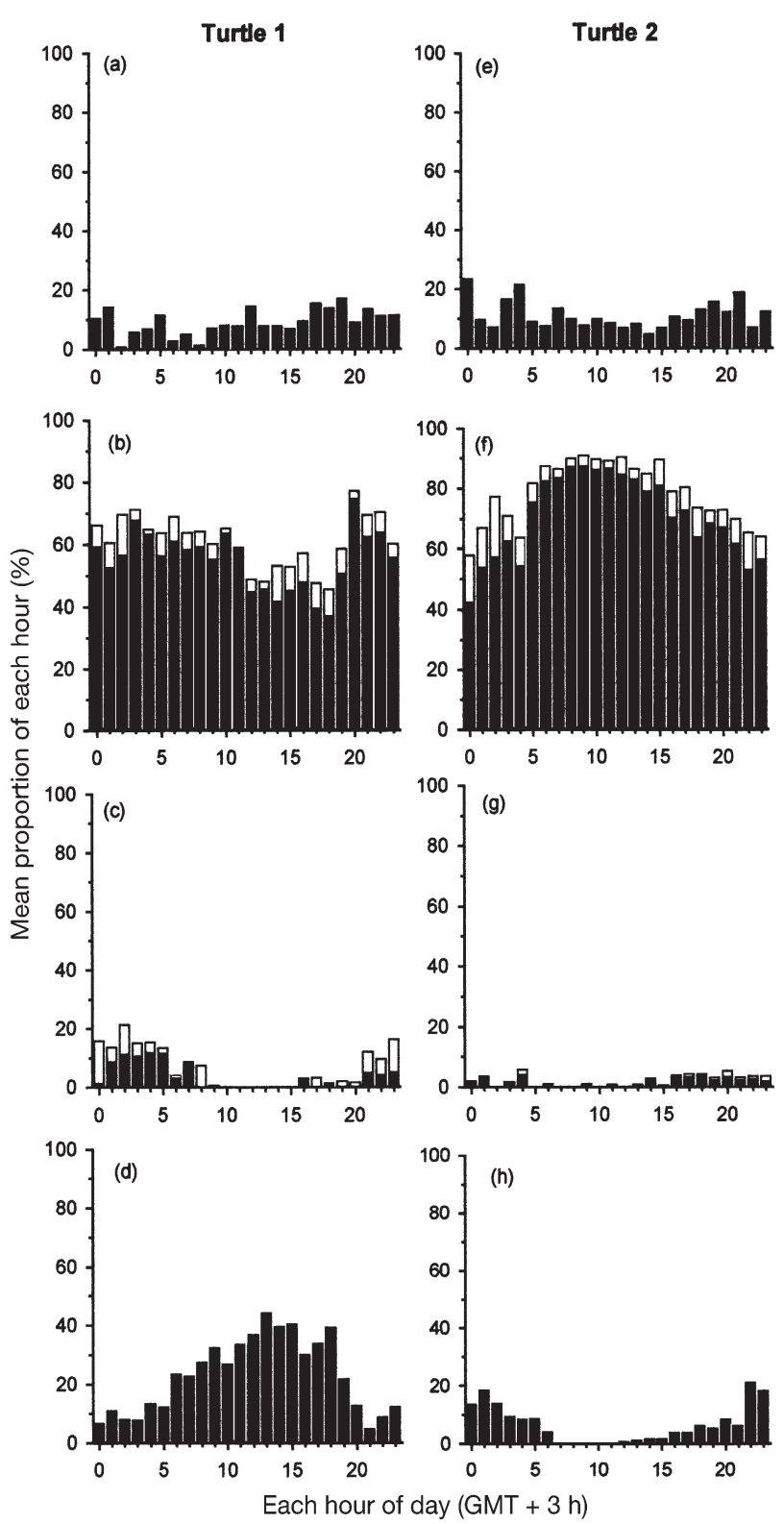

Fig. 4. Mean proportion of each hour attributable to each dive type for Turtle 1 and 2 respectively. (a) and (e) show the time spent at the surface. (b) and (f) show the time spent diving to the seabed (Type 1(a): $\square_{\text {; }}$ Type 1(b): $\square$. (c) and (g) show Type $3 \square$ and Type 4 dives $\mathbf{\square}$. (d) and (h) show type 5 dives
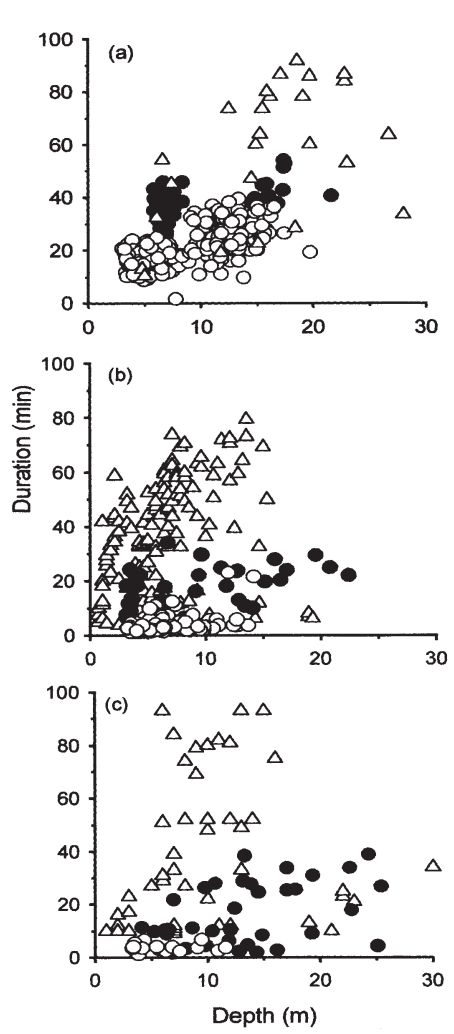

Fig. 5. (a) Relationship between depth and duration for Type 1(a) dives for Turtle $1(0)$, Turtle $2(0)$, and Type 1 dives from Minamikawa et al. (1997) $(\Delta)$. (b) Depth versus duration for Type 3 dives: Turtles $1(\bullet)$, Turtle $2(0)$, and Minamikawa et al. (1997) $(\triangle)$. (c) Depth versus duration for Type 4 dives: Turtle $1(\bullet)$, Turtle $2(0)$, and Minamikawa et al. (1997) $(\Delta)$

\section{Dive depth and duration}

Relationships between dive depth and duration were significant for all dive types, with the exception of Type 4 dives for Turtle 2 (Table 1). Distinct differences existed between the 2 turtles with respect to certain dive types. For example, at comparable depths, the duration of dive Types 1(a), 3 and 4 for Turtle 1 were typically longer than those of Turtle 2 (Fig. 5). Furthermore, when compared with the dives reported in Minamikawa et al. (1997), both turtles remained submerged for shorter periods at any given depth.

\section{Temporal changes in depth utilisation}

The maximum depth recorded for Turtle 1 was $70 \mathrm{~m}$, and $27 \mathrm{~m}$ for Turtle 2. Despite this, the vast majority of the internesting interval for both turtles was spent at depths $<20 \mathrm{~m}$ (Fig. 6). There were, however, differences between the 2 turtles. For Turtle 1, there was a 


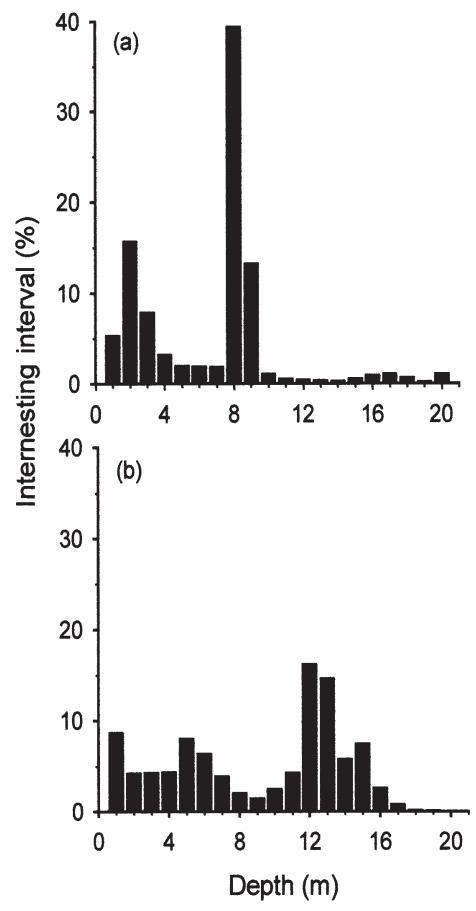

Fig. 6. Frequency distribution showing the depth of occurrence during the internesting interval for (a) Turtle 1 and (b) Turtle 2

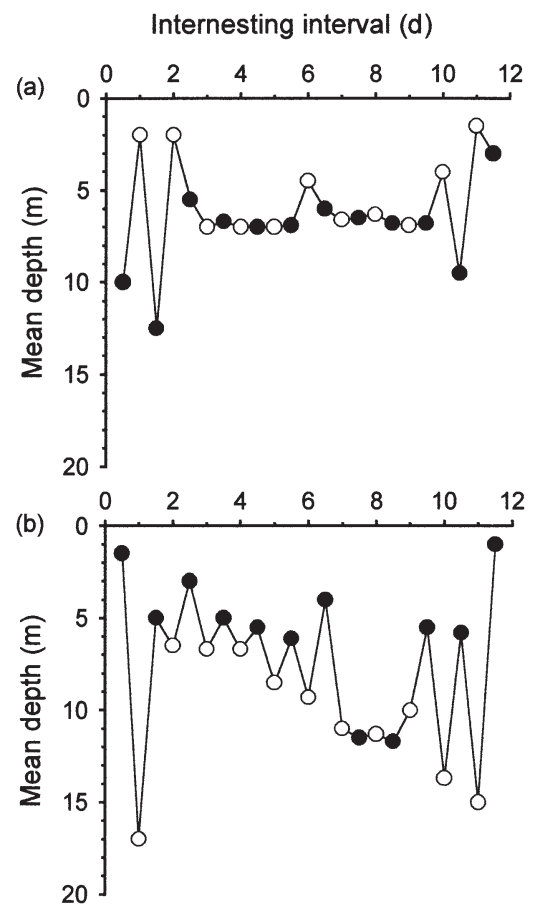

Fig. 7. Mean depth during each day (05:00 to $18: 59 \mathrm{~h})(\mathrm{O})$ and night $(19: 00$ to $04: 59 \mathrm{~h})(\mathbf{})$ of the internesting interval for (a) Turtle 1 and (b) Turtle 2 distinct bi-modality driven by the depth of Type 5 ( 0 to $3 \mathrm{~m}$ ) and Type 1 dives ( 7 to $8 \mathrm{~m}$ ). For Turtle 2, the time spent at different depths was more evenly distributed, although the peaks at 4 to 5 and 11 to $12 \mathrm{~m}$ reflected a bi-modality in the depth of Type 1 dives (Fig. 5a). To test whether such patterns reflected changes on a diel scale, the average depth during each night (19:00 to 04:59 h) and day (05:00 to 18:59 h) were calculated (Fig. 7). For Turtle 1, the observed bi-modality could be largely explained by an increase in Type 5 dives during Days 1, 2, 6, 11 and 12, with the middle part of the internesting interval characterised by Type 1 dives consistently within the 7 to $8 \mathrm{~m}$ depth range. For Turtle 2, there were more pronounced changes in depth throughout the internesting interval. During the first night, Turtle 2 spent a considerable amount of time at the surface $(>5.5 \mathrm{~h})$ after which it appeared to dive to greater depths during Day 1. Following Day 1, mean depth again decreased, with an apparent alternation between daytime and night-time depths over the next few days. Following Day 7, the mean depth increased to $>10 \mathrm{~m}$ as a result of Type 1 (a) dives (thus accounting for the peak at 11 to $12 \mathrm{~m}$ in Fig. 6b) with daytime and night-time depths remaining similar until the final 2 nights when time at the surface again led to a sharp decrease in mean depth (accounting for the peak at $0 \mathrm{~m}$ in Fig. 6b).

\section{DISCUSSION}

As with many egg laying species, we would expect that the need to optimise energy reserves during the nesting season would shape the behaviour of marine turtles. Indeed, during this time turtles will experience an array of physiological changes associated with ovulation, fertilisation, albumin deposition and calcification of $\mathrm{kg}$ quantities of eggs for oviposition. Our results showed a striking predominance of Type 1(a) dives, suggesting that both turtles spent considerable time at the seabed. In light of this, strong inferences can be made regarding depth utilisation, as the maximum depth attained during such dives must represent that of the water column. When superimposed on a bathymetric chart (British Admiralty No. 2074), depths corresponding to Type 1 dives ( 3 to $32 \mathrm{~m}$ ) must have occurred within only $2 \mathrm{~km}$ of the coastline, since further offshore the seabed shelves rapidly to $>200 \mathrm{~m}$. This use of the neritic environment is consistent with green turtles at Cyprus (Hochscheid et al. 1999), reinforcing the importance of the seabed for marine turtles in this area.

Previous studies of diving in marine turtles (e.g. Milsom 1975, Minamikawa et al. 1997) highlight the potential advantages of spending time at the seabed. For example, in addition to the increased benthic for- 
aging opportunities for thecate species, turtles may be able to conserve valuable resources through resting. By adjusting the amount of inspired air to a depth where it intends to dive, a turtle may be able to remain neutrally buoyant for much of a dive (Houghton et al. 2000). As such, given that air becomes compressed with depth in line with Boyle's law, a turtle is able to dive with a larger lung volume when diving deeper and still attain neutral buoyancy. This explains the positive relationship between depth and duration for the dives in the present study, with duration typically increasing with depth. Despite this, the observed differences in duration at comparable depths between the 2 turtles, and also with previously reported data for loggerheads, points to pronounced individual variation in metabolic rate. Certainly some loggerhead turtles do feed at Cyprus, as evidenced by gut content analysis (unpubl.). Furthermore we have recently shown, by direct observation, that adult loggerhead turtles feed close to nesting beaches in Greece (Houghton et al. 2000), suggesting that foraging during the nesting season may be widespread in this species in the Mediterranean. We might tentatively speculate that Turtle 1 (longer dives) spent more time resting on the seabed while Turtle 2 (shorter dives) spent more time foraging.

For Turtle 1, benthic dives decreased at the beginning and end of the internesting interval as a result of increased Type 5 dives. These short, shallow dives show distinct similarities to the sub-surface dives $(<2.5 \mathrm{~m})$ previously reported for green turtles (e.g. Hochscheid et al. 1999). Furthermore, their characteristically smooth inflections between descent and ascent are similar to the 'travelling' dives of other marine vertebrates such as cetaceans (Williams et al. 2000) and penguins (Chappell et al. 1993). In addition to similarities in profile, the depth of Type 5 dives is consistent with the work of Hertel (1966) and Williams (1989), who estimated that, in order to minimise surface drag, travelling dives should be to depths of at least 2 to 3 times an animal's body diameter. Previous studies of green turtles have attributed these shallow dives to movements between the nesting beach and internesting habitat (e.g. Hochscheid et al. 1999), which may explain the predominance of Type 5 dives at the beginning and end of the internesting interval, as the fidelity for nesting sites displayed by sea turtles would require any movement away from the beach to be fully reciprocated. Rudimentary estimations of the extent of movements can be made following the work of Papi et al. (1997), who determined a mean speed of travel for migrating loggerhead turtles of $2.8 \mathrm{~km} \mathrm{~h}^{-1}$. If we take this speed to be broadly representative of that achievable by Turtle 1 , the $66 \mathrm{~h}$ spent travelling to and from the nesting beach equates to a total distance of $185 \mathrm{~km}$.
Extensive periods of Type 5 dives for Turtle 1 occurred during the day followed by Type 3 and 4 dives during the night. Dive Types 3 and 4 have also been reported in loggerhead sea turtles (e.g. Minamikawa et al. 1997, 2000), green turtles (Hochscheid et al. 1999) and sea snakes (Rubinoff et al. 1986, Graham et al. 1987) and are believed to reflect periods of mid-water resting. However, when the water depth is shallow, it is unclear why animals would chose to rest in mid-water rather than on the seabed (Minamikawa et al. 2000). Our results shed light on this conundrum and suggest that mid-water resting is favoured during periods of travelling, while, in the absence of travelling, turtles may opt to conserve resources by resting on the seabed.

The pattern of depth utilisation was very different for Turtle 2, with a distinct alternation between depths during the day and night between Days 2 and 7. Bjorndal (1980) and Ogden et al. (1983) have previously reported diel cycles in marine turtles at foraging grounds in the Bahamas and US Virgin Islands, respectively. In these studies, green turtles were seen to move between night-time rest areas and daytime foraging sites, which may partly explain the pattern in the present study. Furthermore, it is interesting to note that this alternation finished at the same time as Type 1(b) dives (Fig. 2f), implying that a distinct behavioural change occurred at this time, with the ensuing days relating more to the protracted processes associated with nesting.

In conclusion, our results clearly identify the importance of the seabed for loggerhead turtles in Cyprus, in contrast to the far more extensive use of mid-water resting dives for this species in Japan. Our evidence suggests that this dichotomy may reflect differences in the amount of time spent travelling, with mid-water resting occurring when turtles are travelling and, conversely, when little time is spent travelling turtles opt to remain predominantly at the seabed.

Acknowledgements. We thank members of the Marine Turtle Conservation Project, especially Andrew Kelly and Fiona Glen, for field assistance, the Society for the Protection of Turtles in Northern Cyprus and Department of Environmental Protection for logistical assistance, and Alex Ford and Kim Hudson for their constructive comments. This work was supported by grants to G.C.H. from the Natural Environment Research Council of the UK (NERC) and to A.C.B./B.J.G. by British Chelonia Group, European Commission DG1B/1A and MEDASSET.

\section{LITERATURE CITED}

Bjorndal KA (1980) Nutrition and grazing behavior of the green turtle Chelonia mydas. Mar Biol 56:147-154

Chappell MA, Shoemaker VH, Janes DN, Bucher TL, Maloney SK (1993) Diving behaviour during foraging in breeding Adélie penguins. Ecology 74:1204-1214 
Eckert, SA, Nellis, DW, Eckert, KL, Kooyman GL (1986) Diving patterns of two leatherback sea turtles (Dermochelys coriacea) during the internesting interval at Sandy Point, St. Croix, US Virgin Islands. Herpetologica 42:381-388

Graham JB, Gee JH, Motta J, Rubinoff I (1987) Subsurface buoyancy regulation by the sea snake Pelamis platurus. Physiol Zool 60:251-261

Hays GC, Webb PI, Hayes JP, Priede IG, French J (1991) Satellite tracking of a loggerhead turtle (Caretta caretta) in the Mediterranean. J Mar Biol Assoc UK 71:743-746

Hays GC, Luschi P, Papi F, del Seppia C, Marsh R (1999) Changes in behaviour during the internesting period and post-nesting migration for Ascension Island green turtles. Mar Ecol Prog Ser 189:263-273

Hays GC, Adams CR, Broderick AC, Godley BJ, Lucas DJ, Metcalfe JD, Prior AA (2000) The diving behaviour of green turtles at Ascension island. Anim Behav 59:577-586

Hertel H (1966) Structure-form-movement. Reinhold, New York

Hochscheid S, Godley BJ, Broderick AC, Wilson RP (1999) Reptilian diving: highly variable dive patterns in the green turtle Chelonia mydas. Mar Ecol Prog Ser 185:101-112

Houghton JDR, Woolmer A, Hays GC (2000) Sea turtle diving and foraging behaviour around the Greek island of Kefalonia. J Mar Biol Assoc UK 80:761-762

Milsom WK (1975) Development of buoyancy control in juvenile Atlantic loggerhead turtles, Caretta c. caretta. Copeia 1975:671-679

Editorial responsibility: Otto Kinne (Editor),

Oldendorf/Luhe, Germany
Minamikawa S, Naito Y, Uchida I (1997) Buoyancy control of the loggerhead turtle, Caretta caretta. J Ethol 109: $109-118$

Minamikawa S, Naito Y, Sato K, Matsuzawa Y, Bando T, Sakamoto W (2000) Maintenance of neutral buoyancy by depth selection in the loggerhead turtle Caretta caretta. J Exp Biol 203:2967-2975

Ogden JC, Robinson L, Whitlock K, Daganhardt H, Cebula R (1983) Diel foraging patterns in juvenile green turtles (Chelonia mydas L.) in St. Croix United States Virgin Islands. J Exp Biol Mar Ecol 66:199-206

Papi F, Luschi P, Croisio E, Hughes GR (1997) Satellite tracking experiments on the navigational ability and migratory behaviour of the loggerhead turtle Caretta caretta. Mar Biol 129:215-220

Rubinoff I, Graham JB, Motta J (1986) Diving in the sea snake Pelamis platurus in the Gulf of Panama. Mar Biol 91: 181-191

Sakamoto W, Uchida I, Naito Y, Kazuo K, Tujimura M, Sato K (1990) Deep diving behaviour of the loggerhead turtle near the frontal zone. Nippon Suisan Gakkaishi 56: 1453-1433

Williams TM (1989) Swimming by sea otters: adaptations for low energetic cost locomotion. J Comp Physiol 164: 815-824

Williams TM, Davis RW, Fuiman LA, Francis J, LeBoeuf BJ, Horning M, Calambokidis J, Croll DA (2000) Sink or swim: strategies for cost-efficient diving by marine mammals. Science 288:133-136

Submitted: February 14, 2001; Accepted: May 25, 2001

Proofs received from author(s): January 28, 2002 